\title{
Aggregation of Imidazolium Ionic Liquids in Molecular Liquids Studied by Small-Angle Neutron Scattering and NMR
}

\author{
Toshiyuki TaKamuku, ${ }^{* \dagger}$ Yusuke Honda,* Kenta FuJII,* and Shigeharu KitTaKa** \\ *Department of Chemistry and Applied Chemistry, Faculty of Science and Engineering, Saga University, \\ Honjo-machi, Saga 840-8502, Japan \\ **Department of Chemistry, Faculty of Science, Okayama University of Science, \\ 1-1 Ridaicho, Okayama 700-0005, Japan
}

\begin{abstract}
The aggregation of two imidazolium-based ionic liquids, 1-ethly-3-methylimidazolium chloride $\left(\mathrm{EMI}^{+} \mathrm{Cl}^{-}\right)$and $\mathrm{EMI}^{+}$bis(trifluoromethanesulfonyl)amide (EMI ${ }^{+} \mathrm{TFSA}^{-}$), in molecular liquids, water, methanol, acetonitrile, and benzene, has been studied by using the small-angle neutron scattering (SANS) technique. The SANS results have shown that the heterogeneity of $\mathrm{EMI}^{+} \mathrm{Cl}^{-}$-acetonitrile mixtures is significant at high acetonitrile contents, thus, $\mathrm{EMI}^{+} \mathrm{Cl}^{-}$forms clusters in acetonitrile solutions. On the other hand, it has been revealed that $\mathrm{EMI}^{+} \mathrm{Cl}^{-}$is homogeneously dissolved in water and methanol. EMI ${ }^{+} \mathrm{TFSA}^{-}$remarkably aggregates in methanol solutions, while the mixtures of $\mathrm{EMI}^{+} \mathrm{TFSA}^{-}$with acetonitrile and benzene are homogeneous. Furthermore, aggregation of $\mathrm{EMI}^{+} \mathrm{Cl}^{-}$and $\mathrm{EMI}^{+} \mathrm{TFSA}^{-}$in acetonitrile and methanol, respectively, has been examined by using ${ }^{1} \mathrm{H}$ NMR spectroscopy. The mechanism of aggregation of the ionic liquids in the molecular liquids has been discussed on the basis of the properties of cations, anions, and molecular liquids.
\end{abstract}

(Received March 31, 2008; Accepted May 20, 2008; Published October 10, 2008)

\section{Introduction}

Recently, ionic liquids (ILs) have often been utilized as a novel solvent for extraction and condensation. For instance, several ILs were applied to liquid-liquid extraction for metal complexes $^{1,2}$ and biomolecules, ${ }^{3}$ which were transferred from the aqueous phase to the IL one. For preconcentration of phthalic acid esters before high performance liquid chromatography (HPLC), imidazolium ILs were used for a solid-phase extraction technique; ester molecules are adsorbed on IL hemimicelles formed on silica surfaces. ${ }^{4}$ Moreover, ILwater-acetonitrile ternary mixtures, where acetonitrile was added to reduce the viscosity of IL-water mixtures, were employed as a stationary phase to a countercurrent chromatography (CCC). ${ }^{5}$ This revealed that several aromatic compounds can be separated by the CCC using mixtures of ILs and molecular liquids (MLs). Identifying the state of ILs in ML solutions at the molecular level is essential to understand the underlying mechanism of extraction and condensation.

It has been found by many researchers that imidazolium-based ILs aggregate to form micelles in aqueous solutions. ${ }^{6-10}$ Based on thermodynamic parameters, such as excess chemical potentials and excess partial molar enthalpies and entropies, aggregations of 1-butyl-3-methlyimidazolium tetrafluoroborate $\left(\mathrm{BMI}^{+} \mathrm{BF}_{4}^{-}\right)$and $\mathrm{BMI}^{+}$iodide $\left(\mathrm{BMI}^{+} \mathrm{I}^{-}\right)$in aqueous solutions have been discussed. ${ }^{6}$ This study revealed that the ILs form clusters in the range of IL mole fraction $x_{\mathrm{IL}}>\sim 0.5$. To observe aggregation behavior of three imidazolium-based ILs: $\mathrm{BMI}^{+} \mathrm{BF}_{4}^{-}, \mathrm{BMI}^{+} \mathrm{Cl}^{-}$, and 1-octyl-3-methlyimidazolium iodide

† To whom correspondence should be addressed.

E-mail: takamut@cc.saga-u.ac.jp
$\left(\mathrm{OMI}^{+} \mathrm{I}^{-}\right)$, in their aqueous solutions, Bowers et al. have made surface tension, conductivity, and SANS measurements. ${ }^{7}$ For all the aqueous IL solutions, a break point was found in the IL concentration dependence of surface tension and conductivity. This suggests that the ILs aggregate in aqueous solutions at IL concentrations higher than the break point. Moreover, aggregation of the ILs was directly demonstrated by SANS measurements on the IL-ML mixtures. Bowers et al. also estimated the mean radii of IL clusters formed in the mixtures from the SANS intensities measured. The critical aggregation concentrations (cac) for the mixtures determined from the three experiments satisfactorily agreed. Aggregation of ILs in imidazolium IL-water mixtures has also been investigated by absorption and fluorescence spectroscopy with Nile Red dye ${ }^{8}$ and ${ }^{1} \mathrm{H}$ NMR chemical shift measurements. ${ }^{9}$ Recently, aggregation of $\mathrm{BMI}^{+} \mathrm{BF}_{4}^{-}$in aqueous solutions has been discussed on the basis of the $\mathrm{C}-\mathrm{H}$ vibration modes for the alkyl groups within imidazolium cation by means of attenuated total reflection infrared and Raman spectroscopy. ${ }^{10}$

In contrast to IL-water mixtures, there have been a few reports on aggregation behavior of ILs in nonaqueous molecular liquids. Li et al. have investigated the aggregations of $\mathrm{BMI}^{+} \mathrm{BF}_{4}^{-}$and $\mathrm{BMI}^{+}$hexafluorophosphate $\left(\mathrm{BMI}^{+} \mathrm{PF}_{6}^{-}\right)$in ethanol, acetonitrile, ethyl acetate, tetrahydrofuran, and ethanol-water binary solvent by absorption spectroscopy using $N, N$-dimethyl-4-nitroaniline as a probe. ${ }^{11}$ They showed that the degree of aggregation of ILs in the IL-ML mixtures strongly depends on the dielectric constant of the mixtures. However, aggregation of IL in various MLs has not yet been directly observed by using SANS technique.

In the present investigation, SANS experiments at $298 \mathrm{~K}$ have been performed on mixtures of imidazolium-based ILs, $\mathrm{EMI}^{+} \mathrm{Cl}^{-}$ and $\mathrm{EMI}^{+} \mathrm{TFSA}^{-}$, whose melting points are $360 \mathrm{~K}^{12}$ and $247 \mathrm{~K},{ }^{13}$ respectively, with water, methanol, acetonitrile, and benzene, to 
Table 1 Mole fractions of ML, $x_{\mathrm{ML}}$, and volume fractions, vol $\%$, of sample solutions for SANS experiments

\begin{tabular}{|c|c|c|c|c|c|c|c|c|}
\hline \multirow{2}{*}{$\begin{array}{c}\mathrm{EMI}^{+} \mathrm{Cl}^{-}-\mathrm{D}_{2} \mathrm{O} \\
x_{\mathrm{ML}}\end{array}$} & \multirow{2}{*}{$\begin{array}{c}\mathrm{EMI}^{+} \mathrm{Cl}^{-}-\mathrm{CD}_{3} \mathrm{OD} \\
x_{\mathrm{ML}}\end{array}$} & \multirow{2}{*}{$\begin{array}{c}\mathrm{EMI}^{+} \mathrm{Cl}^{-}-\mathrm{CD}_{3} \mathrm{CN} \\
x_{\mathrm{ML}}\end{array}$} & \multicolumn{2}{|c|}{$\mathrm{EMI}^{+} \mathrm{TFSA}^{-}-\mathrm{CD}_{3} \mathrm{OD}$} & \multicolumn{2}{|c|}{$\mathrm{EMI}^{+} \mathrm{TFSA}^{-}-\mathrm{CD}_{3} \mathrm{CN}$} & \multicolumn{2}{|c|}{$\mathrm{EMI}^{+} \mathrm{TFSA}^{-}-\mathrm{C}_{6} \mathrm{D}_{6}$} \\
\hline & & & $x_{\mathrm{ML}}$ & vol\% & $x_{\mathrm{ML}}$ & vol\% & $x_{\mathrm{ML}}$ & vol\% \\
\hline & 0.602 & 0.600 & 0.400 & 9.51 & 0.401 & 12.1 & 0.401 & 18.8 \\
\hline 0.801 & 0.801 & 0.801 & 0.600 & 19.1 & 0.600 & 23.5 & 0.600 & 34.2 \\
\hline 0.900 & 0.900 & 0.900 & 0.800 & 38.7 & 0.800 & 45.1 & 0.700 & 44.7 \\
\hline \multirow[t]{2}{*}{0.950} & 0.950 & 0.950 & 0.900 & 58.6 & 0.901 & 65.1 & & \\
\hline & & & 0.950 & 75.0 & 0.950 & 79.5 & & \\
\hline
\end{tabular}

clarify the aggregation of the ILs in the ML solutions Furthermore, aggregation of the ILs in the mixtures has been examined by using ${ }^{1} \mathrm{H}$ NMR spectroscopy. Based on the present results from SANS and NMR experiments, effects of the MLs on the mixing state of the ILs in the IL-ML mixtures are discussed.

\section{Experimental}

\section{Reagents}

$\mathrm{EMI}^{+} \mathrm{Cl}^{-}$(Aldrich Chemicals) was used without further purification. EMI'TFSA ${ }^{-}$was synthesized according to the conventional method previously described elsewhere. ${ }^{14}$ Water content of $\mathrm{EMI}^{+} \mathrm{TFSA}^{-}$was estimated to be less than $100 \mathrm{ppm}$ by a Karl-Fisher titration.

Deuterated molecular liquids: $\mathrm{D}_{2} \mathrm{O}$ (Cambridge Isotope Laboratories $(\mathrm{CIL}), \mathrm{D}$ content $=99.9 \%), \mathrm{CD}_{3} \mathrm{OD}(\mathrm{CIL}, \mathrm{D}$ content $=99.8 \%), \mathrm{CD}_{3} \mathrm{CN}(\mathrm{CIL}, \mathrm{D}$ content $=99.8 \%)$, and $\mathrm{C}_{6} \mathrm{D}_{6}$ (CIL, D content $=99.5 \%)$, were used for SANS experiments to contrast deuterated ML with undeuterated IL due to the largely different scattering lengths of $\mathrm{D}$ and $\mathrm{H}$ atoms (6.67 and -3.74 $\mathrm{fm}$, respectively). Doubly distilled water, methanol $\left(\mathrm{CH}_{3} \mathrm{OH}\right)$ (Wako Pure Chemicals, grade for HPLC), and acetonitrile $\left(\mathrm{CH}_{3} \mathrm{CN}\right)$ (Wako Pure Chemicals, grade for HPLC) were utilized for ${ }^{1} \mathrm{H}$ NMR experiments.

\section{Sample solutions}

For SANS experiments, $\mathrm{EMI}^{+} \mathrm{Cl}^{-}$solutions were prepared by dissolving crystal $\mathrm{EMI}^{+} \mathrm{Cl}^{-}$in $\mathrm{D}_{2} \mathrm{O}, \mathrm{CD}_{3} \mathrm{OD}$, and $\mathrm{CD}_{3} \mathrm{CN}$ at required $\mathrm{ML}$ mole fractions $x_{\mathrm{ML}}$. $\mathrm{EMI}^{+} \mathrm{TFSA}^{-}$solutions of $\mathrm{CD}_{3} \mathrm{OD}, \mathrm{CD}_{3} \mathrm{CN}$, and $\mathrm{C}_{6} \mathrm{D}_{6}$ were made up by weighing both IL and $\mathrm{ML}$ at required $x_{\mathrm{ML}}$. However, sample solutions of $\mathrm{EMI}^{+} \mathrm{Cl}^{-}$ benzene and $\mathrm{EMI}^{+} \mathrm{TFSA}^{-}$-water were not prepared because of the limit of the solubility for ILs. All sample solutions were prepared under dry nitrogen atmosphere in a glove-box to avoid moisture and replacement of D atoms of heavy water and deuterated methanol with $\mathrm{H}$ ones. Densities of sample solutions were measured at $298 \mathrm{~K}$ with an electronic densimeter (ANTON Paar K. G., DMA60 and DMA602) for analysis of SANS data. The composition of the sample solutions prepared for the SANS experiments is listed in Table 1. $\mathrm{EMI}^{+} \mathrm{Cl}^{-}-\mathrm{CH}_{3} \mathrm{CN}$ and $\mathrm{EMI}^{+} \mathrm{TFSA}^{-}-\mathrm{CH}_{3} \mathrm{OH}$ mixtures at various $\mathrm{ML}$ mole fractions were prepared for ${ }^{1} \mathrm{H}$ NMR measurements.

\section{SANS experiments}

SANS experiments were made at $298 \mathrm{~K}$ on the $\mathrm{EMI}^{+} \mathrm{Cl}^{-}$ solutions of $\mathrm{D}_{2} \mathrm{O}, \mathrm{CD}_{3} \mathrm{OD}$, and $\mathrm{CD}_{3} \mathrm{CN}$ and the EMI'TFSA solutions of $\mathrm{CD}_{3} \mathrm{OD}, \mathrm{CD}_{3} \mathrm{CN}$, and $\mathrm{C}_{6} \mathrm{D}_{6}$ by using the SANS-U spectrometer installed at reactor JRR-3M in the Japan Atomic Energy Agency (JAEA), Tokai, Japan. The sample solutions were kept in a quartz cell of $10 \mathrm{~mm}$ in width, $40 \mathrm{~mm}$ in height, and $2 \mathrm{~mm}$ in sample thickness, and their temperature was controlled within $\pm 0.1 \mathrm{~K}$ during the measurements by circulation of thermostated water around a sample chamber. Two camera lengths, with 1 and $4 \mathrm{~m}$ between the sample and detector positions, were employed to cover the momentum transfer $Q$ (= $4 \pi \lambda^{-1} \sin \theta$ ) ranges of $0.035-0.35$ and $8 \times 10^{-3}-0.1 \AA^{-1}$, respectively. ${ }^{15,16}$ The sample solutions were exposed to neutron beams, whose wavelength $\lambda$ was $7 \AA$ and whose size was $7 \mathrm{~mm}$ in diameter at the sample position, for $10 \mathrm{~min}$ and $1 \mathrm{~h}$ at the camera lengths 1 and $4 \mathrm{~m}$, respectively. However, the quality of the SANS data below $0.09 \AA^{-1}$ was poor, thus, the data in the $Q$ range from 0.09 to $0.35 \AA^{-1}$ were used for a quantitative analysis. The transmission by a sample and a cell was measured with a ${ }^{3} \mathrm{He}$ detector placed at a beam stopper position. The observed intensities were corrected for background by subtraction of intensities of an empty cell, and then normalized by dividing the intensities for each sample solution by those for a low density polyethylene, F200-0, as a standard material. ${ }^{15,16}$ The incoherent scattering was subtracted from the normalized intensities obtained. All parameter values required for the above corrections were taken from the literature. ${ }^{17}$

\section{${ }^{1} H$ NMR spectroscopy}

${ }^{1} \mathrm{H}$ NMR spectra for the $\mathrm{EMI}^{+} \mathrm{Cl}^{-}-\mathrm{CH}_{3} \mathrm{CN}$ and EMI+TFSA-$\mathrm{CH}_{3} \mathrm{OH}$ mixtures have been measured at $298 \pm 0.1 \mathrm{~K}$ using an FT-NMR spectrometer (JEOL, JNM-AL300). The temperature of the sample solutions was kept constant during measurements by mixtures of hot air and a dry nitrogen stream generated from liquid nitrogen. The resolution of ${ }^{1} \mathrm{H}$ NMR was $\pm 0.0012 \mathrm{ppm}$. An external double reference tube (Shigemi), which has a capillary shape with a blown-up sphere at the end, was inserted into the sample tube (Shigemi, PS-001 super precision). Hexamethyldisiloxane (HMDS) (Wako Pure Chemicals, the first grade) was used as a reference substance for ${ }^{1} \mathrm{H}$. The observed chemical shifts were corrected for the volume magnetic susceptibility of a sample solution based on an external double reference method as described below. ${ }^{18-21}$ A couple of NMR signals with the chemical shift $\Delta \delta_{\text {ref }} / \mathrm{ppm}$ is obtained for the reference substance. The chemical shift is related to the volume magnetic susceptibility of the sample liquid $\chi_{\mathrm{s}}$ and the reference substance $\chi_{\mathrm{r}}$, as

$$
\Delta \delta_{\text {ref }}=\kappa\left(\chi_{\mathrm{s}}-\chi_{\mathrm{r}}\right) \times 10^{6}
$$

where $\kappa$ denotes the shape factor for the reference tube. The $\kappa$ value has been determined in advance of sample measurements from the $\Delta \delta_{\text {ref }}$ data for $\mathrm{CDCl}_{3},\left(\mathrm{CD}_{3}\right)_{2} \mathrm{SO}, \mathrm{C}_{6} \mathrm{D}_{12}, \mathrm{C}_{6} \mathrm{D}_{6}$, and $\left(\mathrm{CD}_{3}\right)_{2} \mathrm{CO}$ measured at $298 \mathrm{~K}$, as their $\chi_{\mathrm{s}}$ values are available from the literature. ${ }^{18}$ Hence, the observed chemical shift $\delta_{\text {obs }}$ measured at $298 \mathrm{~K}$ is corrected for the diamagnetic effect as

$$
\delta_{\text {corr }}=\delta_{\text {obs }}-(4 \pi / 3)\left(\chi_{\mathrm{s}}-\chi_{\mathrm{r}}\right) \times 10^{6}=\delta_{\text {obs }}-(4 \pi / 3 \kappa) \Delta \delta_{\text {ref }}
$$

where the $\delta_{\text {obs }}$ value is the shift from the reference signal in a capillary. 


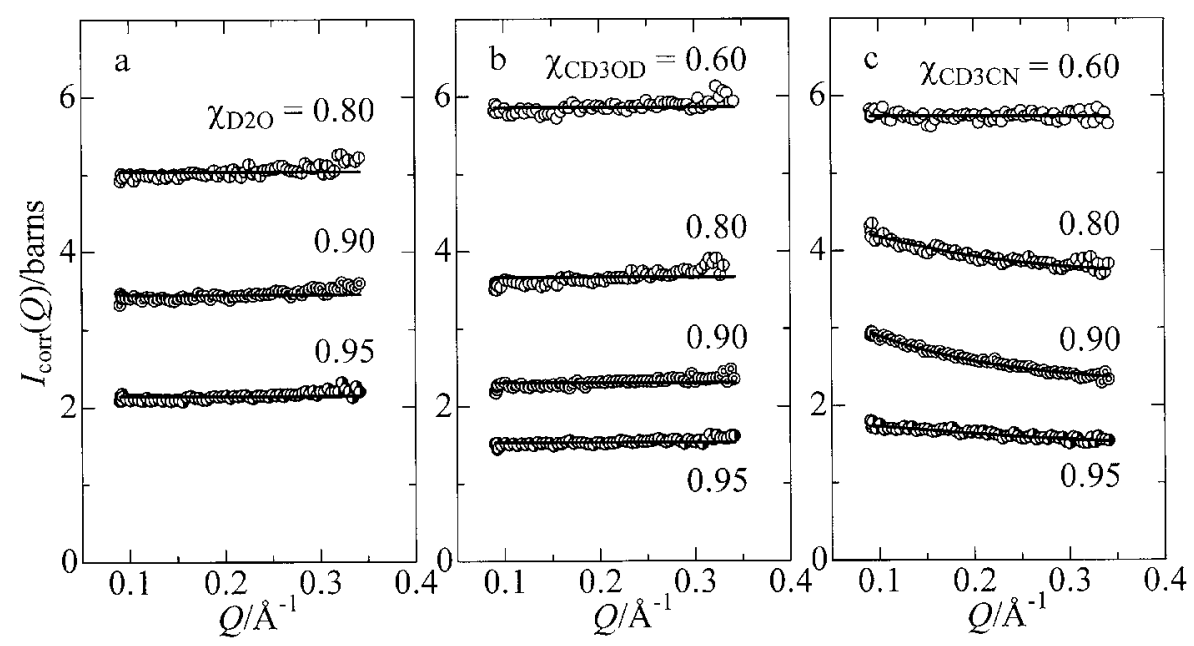

Fig. 1 Normalized SANS intensities for $\mathrm{EMI}^{+} \mathrm{Cl}^{-}$mixtures of (a) $\mathrm{D}_{2} \mathrm{O}$, (b) $\mathrm{CD}_{3} \mathrm{OD}$, and (c) $\mathrm{CD}_{3} \mathrm{CN}$ at various ML mole fractions. Circles and solid lines represent the experimental values and the theoretical ones obtained from a least-squares refinement procedure using Eq. (3), respectively.

\section{Results and Discussion}

\section{SANS experiments}

In Fig. 1a, the normalized neutron scattering intensities $I_{\text {corr }}(Q)$ for the $\mathrm{EMI}^{+} \mathrm{Cl}^{-}-\mathrm{D}_{2} \mathrm{O}$ mixtures at water mole fractions $x_{\mathrm{D} 2 \mathrm{O}}=$ $0.8,0.9$, and 0.95 are depicted. The intensities for the mixtures are almost flat over the $Q$ range from 0.09 to $0.35 \AA^{-1}$ or slightly decline to the low $Q$ side. This suggests that $\mathrm{EMI}^{+}$and $\mathrm{Cl}^{-}$are homogenously dissolved in water over the mole fraction range examined. As seen in Fig. 1b, the normalized scattering intensities for the $\mathrm{EMI}^{+} \mathrm{Cl}^{-}-\mathrm{CD}_{3} \mathrm{OD}$ mixtures at methanol mole fractions $x_{\mathrm{CD} 3 \mathrm{OD}}=0.6,0.8,0.9$, and 0.95 reveal that $\mathrm{EMI}^{+} \mathrm{Cl}^{-}$is also homogeneously dissolved in methanol. This is mainly caused by strong solvation of chloride ions by water and methanol molecules due to their high electron-acceptability, as shown by the Mayer-Gutmann's acceptor numbers $\left(A_{\mathrm{N}}=54.8\right.$ and 41.3 , respectively). ${ }^{22}$ Additionally, water and methanol molecules may interact with the hydrogen atoms of the imidazolium ring by hydrogen bonding because of the high electron-donicity, as indicated by Gutmann's donor numbers $\left(D_{\mathrm{N}}=18.0\right.$ and 19.0 , respectively $) .^{22}$

As shown in Fig. 1c, the SANS intensities for the $\mathrm{EMI}^{+} \mathrm{Cl}^{-}$ $\mathrm{CD}_{3} \mathrm{CN}$ mixtures at acetonitrile mole fractions $x_{\mathrm{CD} 3 \mathrm{CN}}=0.8$ and 0.9 are clearly observed, whereas those for the mixture at $x_{\mathrm{CD} 3 \mathrm{CN}}$ $=0.6$ scarcely appear. When the mole fraction increases to 0.95 , the SANS intensities for the mixture decrease. The features of the SANS spectra suggest that $\mathrm{EMI}^{+} \mathrm{Cl}^{-}$is not homogeneously dissolved in acetonitrile; $\mathrm{EMI}^{+} \mathrm{Cl}^{-}$forms clusters in the mixtures when the $x_{\mathrm{CD} 3 \mathrm{CN}}$ reaches 0.8 , the aggregation of the ILs in the mixture at $x_{\mathrm{CD} 3 \mathrm{CN}}=0.9$ is most enhanced among the mole fractions studied, and then, the aggregation is reduced again at $x_{\mathrm{CD} 3 \mathrm{CN}}=0.95$. This is because acetonitrile molecules weakly interact with chloride ions by the ion-dipole interactions due to the large dipole moment $\left(13.06 \times 10^{-30} \mathrm{C} \mathrm{m}\right)$ rather than the low electron-acceptability $\left(A_{\mathrm{N}}=19.3\right) .^{22}$ Furthermore, acetonitrile molecules cannot easily form hydrogen bonds with $\mathrm{EMI}^{+}$ because of the low electron-donicity $\left(D_{\mathrm{N}}=14.1\right) .{ }^{22}$ In the weak solvent of acetonitrile, thus, $\mathrm{EMI}^{+}$and $\mathrm{Cl}^{-}$interact with each other to form clusters by both charge-charge interaction and hydrogen bonds. ${ }^{23-27}$ On the other hand, acetonitrile molecules
Table 2 Ornstein-Zernike correlation lengths $\xi$ for $\mathrm{EMI}^{+} \mathrm{Cl}^{-}-\mathrm{CD}_{3} \mathrm{CN}$ and $\mathrm{EMI}^{+} \mathrm{TFSA}{ }^{-}-\mathrm{CD}_{3} \mathrm{OD}$ mixtures estimated from SANS experiments

\begin{tabular}{ccccc}
\hline \multicolumn{2}{c}{$\mathrm{EMI}^{+} \mathrm{Cl}^{-}-\mathrm{CD}_{3} \mathrm{CN}$} & & \multicolumn{2}{c}{$\mathrm{EMI}^{+} \mathrm{TFSA}^{-}-\mathrm{CD}_{3} \mathrm{OD}$} \\
\cline { 2 - 4 } \cline { 5 - 6 }$x_{\mathrm{ML}}$ & $\xi / \AA$ & & $x_{\mathrm{ML}}$ & $\xi / \AA$ \\
\hline 0.801 & $5.9(1)$ & & 0.800 & $4.7(1)$ \\
0.900 & $6.4(1)$ & & 0.900 & $5.8(1)$ \\
0.950 & $3.9(1)$ & & 0.950 & $4.5(1)$ \\
\hline
\end{tabular}

The values in the parentheses are standard deviations for the last figure.

aggregate with themselves by the dipole-dipole interactions among them to form clusters in the mixtures. ${ }^{28}$

To quantitatively clarify aggregation of $\mathrm{EMI}^{+} \mathrm{Cl}^{-}$in the three systems, the Ornstein-Zernike fits were made on the scattering intensities through

$$
I_{\text {corr }}(Q)=\frac{I_{0}}{1+\xi^{2} Q^{2}}+\text { B.G., }
$$

where $I_{0}$ represents the scattering intensities at $Q=0, \xi$ is the Ornstein-Zernike correlation length, which gives the mean distance among clusters of deuterated ML molecules, and B.G. is background intensities. The solid lines in Fig. 1 indicate the results of least-squares fits using Eq. (3). The theoretical values reproduce well the observed ones. The correlation lengths $\xi$ estimated for the $\mathrm{EMI}^{+} \mathrm{Cl}^{-}-\mathrm{CD}_{3} \mathrm{CN}$ mixtures at $x_{\mathrm{CD} 3 \mathrm{CN}}=0.8,0.9$, and 0.95 are listed in Table 2. The values for the $\mathrm{EMI}^{+} \mathrm{Cl}^{-}$ $\mathrm{CD}_{3} \mathrm{CN}$ mixture at $x_{\mathrm{CD} 3 \mathrm{CN}}=0.6$ and the $\mathrm{EMI}^{+} \mathrm{Cl}^{-}-\mathrm{D}_{2} \mathrm{O}$ and $\mathrm{EMI}^{+} \mathrm{Cl}^{-}-\mathrm{CD}_{3} \mathrm{OD}$ mixtures at all the mole fractions examined could not be estimated because the SANS intensities were not strong enough. The $\xi$ value for the $\mathrm{EMI}^{+} \mathrm{Cl}^{-}-\mathrm{CD}_{3} \mathrm{CN}$ mixtures increases with increasing $x_{\mathrm{CD} 3 \mathrm{CN}}$ to 0.9 and decreases at $x_{\mathrm{CD} 3 \mathrm{CN}}=$ 0.95. It is thus shown that aggregation of $\mathrm{EMI}^{+} \mathrm{Cl}^{-}$in the acetonitrile solutions occurs in the narrow acetonitrile-rich range centered at $x_{\mathrm{CD} 3 \mathrm{CN}}=0.9$. The maximum $\xi$ value suggests that acetonitrile clusters are formed with the distance $\sim 6 \AA$ among them in the mixture at $x_{\mathrm{CD} 3 \mathrm{CN}}=0.9$. 


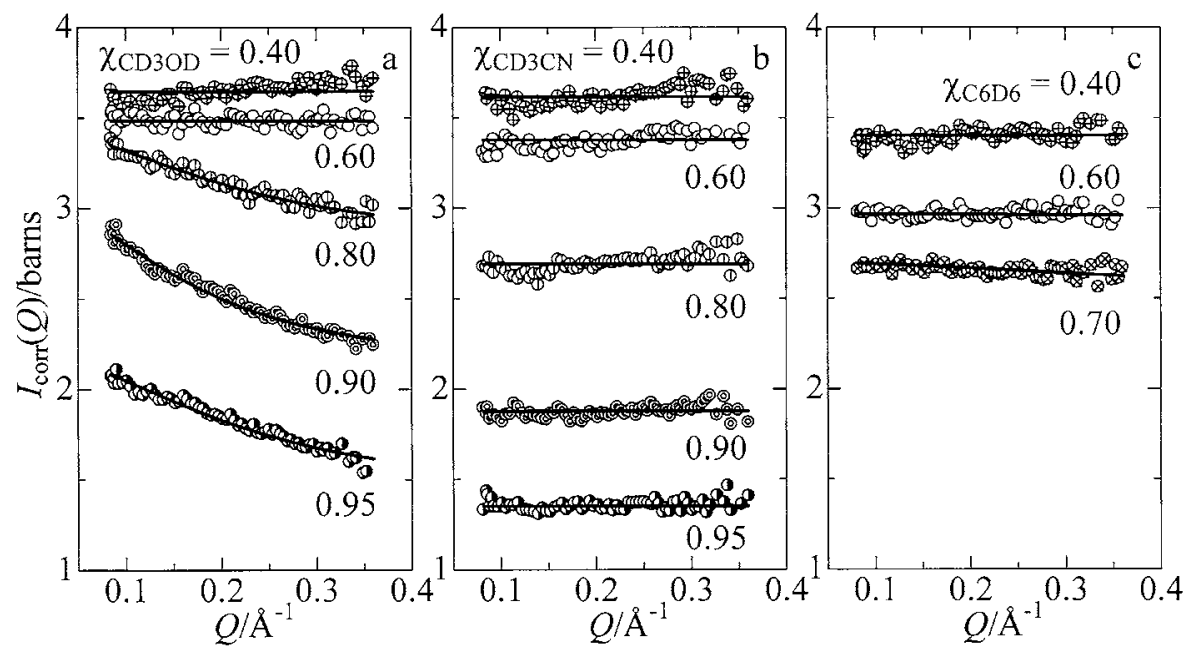

Fig. 2 Normalized SANS intensities for EMI'TFSA- mixtures of (a) $\mathrm{CD}_{3} \mathrm{OD}$, (b) $\mathrm{CD}_{3} \mathrm{CN}$, and (c) $\mathrm{C}_{6} \mathrm{D}_{6}$ at various ML mole fractions. The types of the lines are the same as those used in Fig. 1.

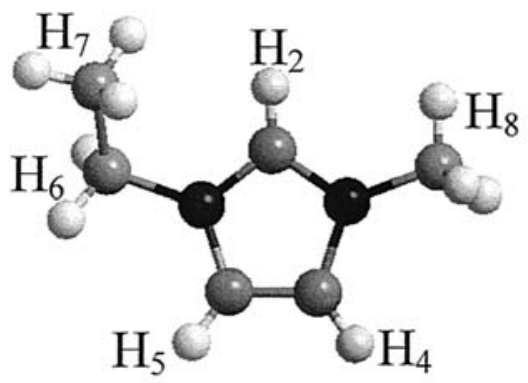

Fig. 3 Notation of hydrogen atoms within $\mathrm{EMI}^{+}$.

Figures $2 \mathrm{a}$ and $2 \mathrm{~b}$ show the neutron scattering intensities for the $\mathrm{EMI}^{+} \mathrm{TFSA}^{-}-\mathrm{CD}_{3} \mathrm{OD}$ and $\mathrm{EMI}^{+} \mathrm{TFSA}^{-}-\mathrm{CD}_{3} \mathrm{CN}$ mixtures, respectively, in the $x_{\mathrm{ML}}$ range from 0.4 to 0.95 , which corresponds to the volume fraction range from $\sim 10$ to $\sim 80 \%$. The SANS intensities for the former at $x_{\mathrm{CD} 3 \mathrm{OD}}=0.8,0.9$, and 0.95 are significant, while those for the latter at all the mole fractions are scarcely observed. Thus, aggregation of $\mathrm{EMI}^{+} \mathrm{TFSA}^{-}$takes place in the methanol solutions, but does not in the acetonitrile solutions. The results for the EMI'TFSA systems are opposite to those for the $\mathrm{EMI}^{+} \mathrm{Cl}^{-}$systems. The negative charge of TFSA $^{-}$distributes over the $\mathrm{O}_{2} \mathrm{~S}-\mathrm{N}-\mathrm{SO}_{2}$ moiety, i.e., the charge density of TFSA- is much lower than that of chloride ion. Thus, methanol molecules cannot strongly interact with $\mathrm{TFSA}^{-}$. In the $\mathrm{EMI}^{+} \mathrm{TFSA}^{-}$-methanol mixtures, methanol molecules prefer to aggregate with themselves by hydrogen bonding, and TFSA ${ }^{-}$interact with $\mathrm{EMI}^{+}$to form clusters by the charge-charge interactions. The correlation lengths $\xi$ for the $\mathrm{EMI}^{+}{ }^{-} \mathrm{TFSA}^{-}-\mathrm{CD}_{3} \mathrm{OD}$ mixtures estimated from the Ornstein-Zernike fits are summarized in Table 2. In the methanol solution at $x_{\mathrm{CD} 30 \mathrm{D}}=0.9$, aggregation of EMI ${ }^{+} \mathrm{TFSA}^{-}$is most enhanced in the mole fraction range studied, and methanol molecules form clusters with the distance $\sim 6 \AA$ among them. On the contrary, acetonitrile molecules interact with both $\mathrm{EMI}^{+}$ and TFSA- by ion-dipole interaction. In particular, the dipoledipole interaction may easily act between acetonitrile molecule and the $C_{1}$ conformer of TFSA-, where the two $\mathrm{CF}_{3}$ groups are set to the cis position with respect to the $\mathrm{O}_{2} \mathrm{~S}-\mathrm{N}-\mathrm{SO}_{2}$ moiety, due to the large dipole moment $\left(15 \times 10^{-30} \mathrm{C} \mathrm{m}\right)$ of the conformer, as estimated in the previous DFT study. ${ }^{29}$ Thus, $\mathrm{EMI}^{+}, \mathrm{TFSA}^{-}$, and acetonitrile molecules are homogeneously mixed over the entire mole fraction range.

Figure $2 \mathrm{c}$ shows the normalized neutron scattering intensities of EMI ${ }^{+}{ }^{+} \mathrm{TSA}^{-}-\mathrm{C}_{6} \mathrm{D}_{6}$ mixtures at $x_{\mathrm{C} 6 \mathrm{D} 6}=0.4,0.6$, and 0.7, which correspond to the volume fractions 20, 30, and 45\%, respectively. The SANS intensities for the mixtures at $x_{\mathrm{C} 6 \mathrm{D} 6}=$ 0.4 and 0.6 are not observed, showing that EMI $^{+}$TFSA $^{-}$is homogeneously mixed with benzene at the mole fractions. On the other hand, the SANS intensities for the mixture at $x_{\mathrm{C} 6 \mathrm{D} 6}=$ 0.7 are only slightly observed, though the $\xi$ value could not be determined with high reliability. Results reveal that the heterogeneity of the mixture rises at $x_{\mathrm{C} 6 \mathrm{D} 6}=0.7$ because the mole fraction is close to the limit of the solubility. As shown in the previous investigations on mixtures of imidazolium-based ILs and benzene, ${ }^{30-33}$ the benzene molecules interact with the imidazolium rings by the $\pi-\pi$ interaction. In addition, the crystal structure of EMI ${ }^{+}{ }^{-} F^{-} A^{-}-$benzene mixtures previously reported has shown some hydrogen bonds between the oxygen atoms of $\mathrm{TFSA}^{-}$and the hydrogens of benzene molecule. ${ }^{33}$ Hence, these interactions lead to homogeneous mixtures of benzene and $\mathrm{EMI}^{+} \mathrm{TFSA}^{-}$. However, $\mathrm{EMI}^{+} \mathrm{TFSA}^{-}$and benzene are not miscible with each other at mole fractions higher than $x_{\mathrm{C} 6 \mathrm{D} 6} \approx 0.75$. This is consistent with the fact that one imidazolium ring and two benzene molecules form a sandwich structure with the $\pi-\pi$ interaction, as observed in dimethylimidazolium $\left(\mathrm{DMI}^{+}\right) \mathrm{PF}_{6}{ }^{-}$-benzene mixture. ${ }^{30}$ Thus, benzene molecules will not be easily accepted into EMI ${ }^{+}$TFSA $^{-}$ beyond the molar ratio of IL to benzene 1:2, which corresponds to $x_{\mathrm{C} 6 \mathrm{D} 6}=0.67$.

\section{${ }^{1} H$ NMR chemical shift}

The mole fraction dependence of the ${ }^{1} \mathrm{H}$ chemical shifts for the hydrogen atoms within $\mathrm{EMI}^{+}$(see Fig. 3 for numbering $\mathrm{H}$ atoms) in the $\mathrm{EMI}^{+} \mathrm{Cl}^{-}-\mathrm{CH}_{3} \mathrm{CN}$ and $\mathrm{EMI}^{+} \mathrm{TFSA}^{-}-\mathrm{CH}_{3} \mathrm{OH}$ mixtures is depicted in Figs. 4 and 5, respectively. As seen in the figures, a break point clearly appears at $x_{\mathrm{ML}} \approx 0.8$. The break point is attributable to the formation of IL clusters in the mixtures at $x_{\mathrm{ML}} \geq \sim 0.8$.

Figure 4 indicates that the NMR data for the hydrogen atoms $\mathrm{H}_{2}, \mathrm{H}_{4}$, and $\mathrm{H}_{5}$ of the imidazolium ring in the $\mathrm{EMI}^{+} \mathrm{Cl}^{-}-\mathrm{CH}_{3} \mathrm{CN}$ mixtures change with increasing $x_{\mathrm{CH} 3 \mathrm{CN}}$ more than those for $\mathrm{H}_{6}$, 

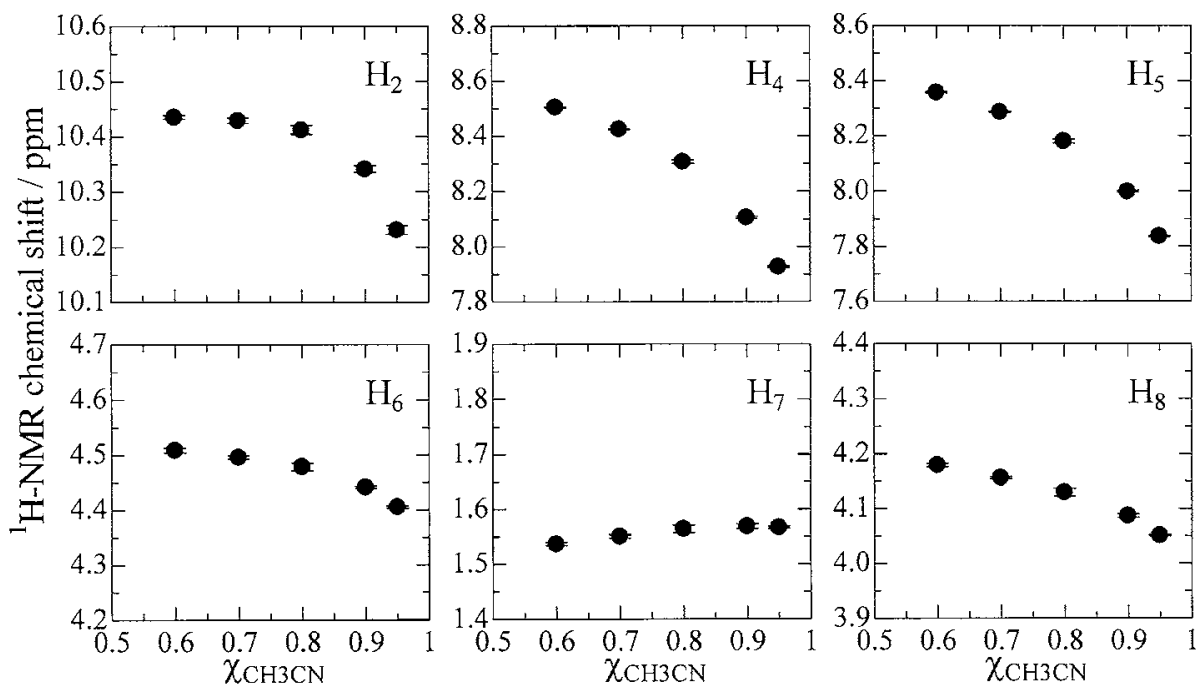

Fig. 4 Variation of ${ }^{1} \mathrm{H}$ NMR chemical shifts for the hydrogen atoms within $\mathrm{EMI}^{+}$in $\mathrm{EMI}^{+} \mathrm{Cl}^{-}-$ $\mathrm{CH}_{3} \mathrm{CN}$ mixtures with acetonitrile mole fraction. HMDS was used as a reference.
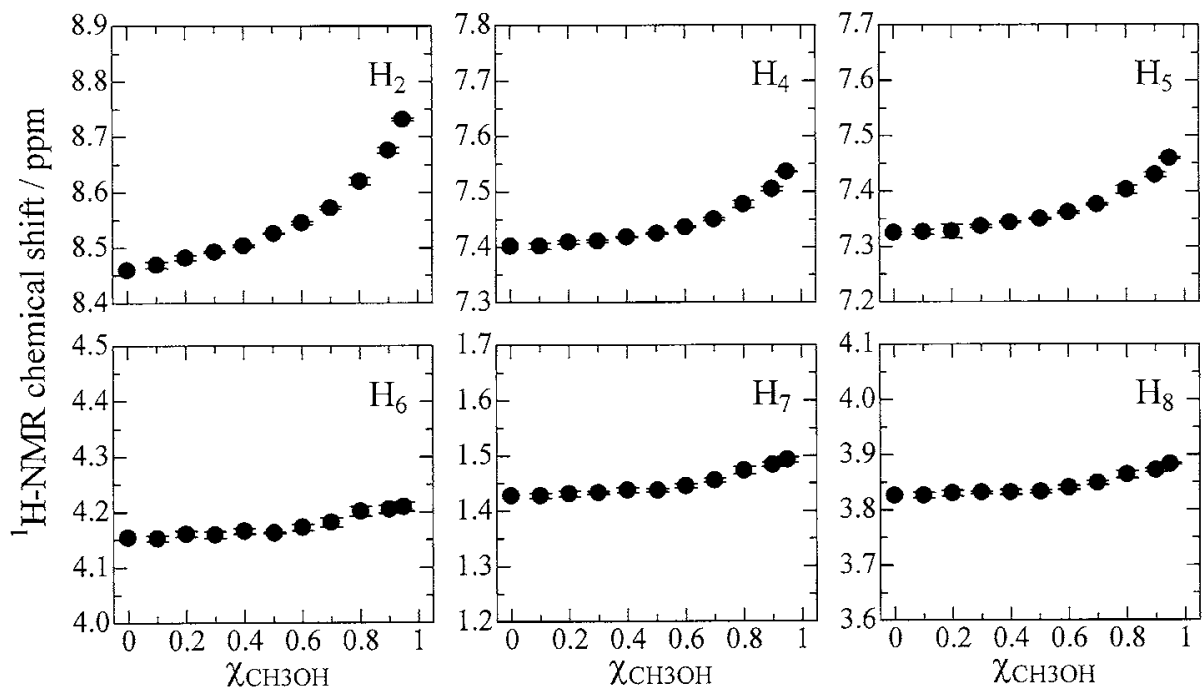

Fig. 5 Variation of ${ }^{1} \mathrm{H}$ NMR chemical shifts for the hydrogen atoms within $\mathrm{EMI}^{+}$in $\mathrm{EMI}^{+} \mathrm{TFSA}^{-}-\mathrm{CH}_{3} \mathrm{OH}$ with methanol mole fraction. HMDS was used as a reference.

$\mathrm{H}_{7}$, and $\mathrm{H}_{8}$ of the alkyl groups. The NMR features may arise mainly from the hydrogen bonds between the ring hydrogens and the chloride ions. The crystal X-ray diffraction and molecular vibration studies have shown the hydrogen bonds between the ring hydrogens and halide ions in 1-alkyl-3methlyimidazolium halide, such as $\mathrm{BMI}^{+} \mathrm{Cl}^{-} \cdot{ }^{23-26}$ Additionally, the neutron diffraction investigation with empirical potential structure refinement has revealed that the hydrogen bonds between the ring hydrogens and chloride ions are formed even in the liquid state of $\mathrm{DMI}^{+} \mathrm{Cl}^{-} .{ }^{27}$ In the $\mathrm{EMI}^{+} \mathrm{Cl}^{-}-\mathrm{CH}_{3} \mathrm{CN}$ mixtures below the break point $x_{\mathrm{CH} 3 \mathrm{CN}}<\sim 0.8$, the inherent structure of $\mathrm{EMI}^{+} \mathrm{Cl}^{-}$may be kept even in the solutions because of the hydrogen bonds between cations and anions. Hence, the NMR data moderately change with the increase in the ML mole fraction. When the $x_{\mathrm{CH} 3 \mathrm{CN}}$ rises beyond $\sim 0.8$, the inherent structure of the IL is gradually disrupted in the mixtures, and both IL and ML clusters are formed. Thus, the hydrogen bonds between the ring hydrogens and chloride ions weaken, leading to the significant high field shifts of the NMR signals. Figure 4 also shows that the changes in the chemical shifts of $\mathrm{H}_{4}$ and $\mathrm{H}_{5}$ with mole fraction are more remarkable than that of $\mathrm{H}_{2}$. The hydrogen bonds between $\mathrm{H}_{4}$ or $\mathrm{H}_{5}$ and chloride ions more easily weaken with increasing acetonitrile mole fraction than that for $\mathrm{H}_{2}$ because the charge of $\mathrm{H}_{4}$ and $\mathrm{H}_{5}$ is less positive than that of $\mathrm{H}_{2}$. 26,27

Figure 5 shows that the NMR data for the EMI+TFSA-$\mathrm{CH}_{3} \mathrm{OH}$ mixtures shift to a low magnetic field with increasing $x_{\mathrm{ML}}$, while those for the $\mathrm{EMI}^{+} \mathrm{Cl}^{-}-\mathrm{CH}_{3} \mathrm{CN}$ mixtures change to a high field. In accordance with the crystal structure of EMI $^{+}$TFSA $^{-}$studied by X-ray diffraction, the $\mathrm{SO}_{2}$ moieties of TFSA $^{-}$are located on a plane involving the imidazolium rings to form the $\mathrm{S}=\mathrm{O} \cdots \mathrm{H}-\mathrm{C}$ hydrogen bonds with the ring hydrogens. ${ }^{13}$ However, our recent investigation on the liquid structure of EMI $^{+}$TFSA $^{-}$by using X-ray diffraction, molecular dynamics simulation, and NMR techniques has shown that $\mathrm{EMI}^{+}$is surrounded by four TFSA $^{-}$with the distance $\sim 6 \AA$ between 
cation and anion, but the hydrogen bonds between the ring hydrogens and the $\mathrm{SO}_{2}$ moieties are broken down in the liquid. ${ }^{34}$ Thus, the low field shifts of the NMR data for the EMI'TFSA$\mathrm{CH}_{3} \mathrm{OH}$ mixtures may result from the change in the interaction between the ring hydrogens and methanol molecules with increasing $x_{\mathrm{CH} 3 \mathrm{OH}}$. In the mixtures at $x_{\mathrm{CH} 3 \mathrm{OH}}<\sim 0.7$, the inherent structure of EMI $^{+}$TFSA $^{-}$created by the charge-charge interaction between cation and anion predominates, and methanol molecules may not remarkably interact with the hydrogen atoms of the imidazolium ring. Thus, the NMR data for $\mathrm{H}_{2}, \mathrm{H}_{4}$, and $\mathrm{H}_{5}$ moderately shift with increasing $x_{\mathrm{CH} 3 \mathrm{OH}}$. When methanol molecules increase beyond $x_{\mathrm{CH} 3 \mathrm{OH}} \approx 0.7$, EMI $^{+}$TFSA $^{-}$and methanol molecules begin to form their respective clusters, and methanol molecules may interact with the ring hydrogens of $\mathrm{EMI}^{+}$by hydrogen bonding. Thus, the NMR data for $\mathrm{H}_{2}, \mathrm{H}_{4}$, and $\mathrm{H}_{5}$ significantly shift to the low field with increasing $x_{\mathrm{CH} 3 \mathrm{OH}}$. In particular, the shift for the $\mathrm{H}_{2}$ atom with $x_{\mathrm{CH} 3 \mathrm{OH}}$ is most significant among the hydrogens due to having the highest positive charge.

\section{Acknowledgements}

This work was supported partly by Grants-in-Aid (No. 19550022 (T. T.) and 19003963 (K. F.)) from the Ministry of Education, Culture, Sports, Science, and Technology, Japan. The SANS experiments were performed using the SANS-U spectrometer of the Institute for Solid State Physics, the University of Tokyo (Proposal No. 7632). The density and NMR measurements for the sample solutions were carried out at the Analytical Research Center for Experimental Sciences of Saga University.

\section{References}

1. T. Ajioka, S. Oshimab, and N Hirayama, Talanta, 2008, 74, 903.

2. X. Q. Suna, B. Peng, J. Chena, D. Q. Li, and F. Luob, Talanta, 2008, 74, 1071.

3. Z. Du, Y.-L. Yu, and J.-H. Wang, Chem.-Eur. J., 2007, 13, 2130.

4. J. Li, Y. Cai, Y. Shi, S. Mou, and G. Jiang, Talanta, 2008, 74,498 .

5. A. Berthod and S. Carda-Broch, Anal. Bioanal. Chem., 2004, 380, 168.

6. H. Katayanagi, K. Nishikawa, H. Shimozaki, K. Miki, P. Westh, and Y. Koga, J. Phys. Chem. B, 2004, 108, 19451.

7. J. Bowers, C. P. Butts, P. J. Martin, and M. C. VergaraGutierrez, Langmuir, 2004, 20, 2191.

8. Z. Miskolczy, K. Sebök-Nagy, L. Biczók, and S. Göktürk, Chem. Phys. Lett., 2004, 400, 296.

9. T. Singh and A. Kumar, J. Phys. Chem. B, 2007, 111, 7843.

10. Y. Jeon, J. Sung, D. Kim, C. Seo, H. Cheong, Y. Ouchi, R. Ozawa, and H. Hamaguchi, J. Phys. Chem. B, 2008, 112, 923.
11. W. Li, Z. Zhang, J. Zhang, B. Han, B. Wang, M. Hou, and Y. Xie, Fluid Phase Equilib., 2006, 248, 211.

12. L. P. Wasserscheid and T. Welton, "Ionic Liquids in Synthesis", 2003, Wiley-VCH, Weinheim.

13. A. R. Choudhury, N. Winterton, A. Steiner, A. I. Cooper, and K. A. Johnson, CrystEngComm., 2006, 8, 742.

14. P. Nockemann, K. Binnemans, and K. Driesen, Chem. Phys. Lett., 2005, 415, 131.

15. S. Okabe, M. Nagao, T. Karino, S. Watanabe, T. Adachi, H. Shimizu, and M. Shibayama, J. Appl. Crystallogr., 2005, 38,1035 .

16. S. Okabe, T. Karino, M. Nagao, S. Watanabe, and M. Shibayama, Nucl. Instrum. Methods Phys. Res., Sect. A, 2007, 572, 853.

17. V. F. Sears, "Thermal-Neutron Scattering Lengths and Cross Sections for Condensed-Matter Research", 1984, Chalk River Lab., Ontario.

18. K. Mizuno, Y. Tamiya, and M. Mekata, Pure Appl. Chem., 2004, 76, 105.

19. K. Mizuno, S. Imafuji, T. Ochi, T. Ohta, and S. Maeda, J. Phys. Chem. B, 2000, 104, 11001.

20. K. Momoki and Y. Fukazawa, Anal. Chem., 1990, 62, 1665.

21. K. Momoki and Y. Fukazawa, Anal. Sci., 1994, 10, 53.

22. V. Gutmann, "The Donor-Acceptor Approach to Molecular Interactions", 1978, Plenum Press, New York.

23. S. Saha, S. Hayashi, A. Kobayashi, and H. Hamaguchi, Chem. Lett., 2003, 32, 740.

24. A. K. Abdul-Sada, A. M. Greenway, P. B. Hitchcock, T. J. Mohammed, K. R. Seddon, and J. A. Zora, J. Chem. Soc. Chem. Commun., 1986, 1753.

25. A. G. Avent, P. A. Chaloner, M. P. Day, K. R. Seddon, and T. Welton, J. Chem. Soc., Dalton Trans., 1994, 3405.

26. A. Elaiwi, P. B. Hitchcock, K. R. Seddon, N. Srinivasan, Y.M. Tan, T. Welton, and J. A. Zora, J. Chem. Soc., Dalton Trans., 1995, 3467.

27. C. Hardacre, J. D. Holbrey, S. E. J. McMath, D. T. Bowron, and A. K. Soper, J. Chem. Phys., 2003, 118, 273.

28. T. Takamuku, M. Tabata, M. Kumamoto, A. Yamaguchi, J. Nishimoto, H. Wakita, and T. Yamaguchi, J. Phys. Chem. B, 1998, 102, 8880.

29. K. Fujii, R. Kanzaki, T. Takamuku, T. Fujimori, Y. Umebayashi, and S. Ishiguro, J. Phys. Chem. B, 2006, 110, 8179 .

30. M. Deetlefs, C. Hardacre, M. Nieuwenhuyzen, O. Sheppard, and A. K. Soper, J. Phys. Chem. B, 2005, 109, 1593.

31. C. G. Hanke, A. Johansson, J. B. Harper, and R. M. Lynden-Bell, Chem. Phys. Lett., 2003, 374, 85.

32. J. D. Holbrey, W. M. Reichert, M. Nieuwenhuyzen, O. Sheppard, C. Hardacre, and R. D. Rogers, Chem. Commun., 2003, 476.

33. J. Łachwa, I. Bento, M. T. Duarte, J. N. C. Lopes, and L. P. N. Rebelo, Chem. Commun., 2006, 2445.

34. K. Fujii, Y. Soejima, Y. Kyoshoin, S. Fukuda, R. Kanzaki, Y. Umebayashi, T. Yamaguchi, S. Ishiguro, and T. Takamuku, J. Phys. Chem. B, 2008, 112, 4329. 